\title{
Formação e atitude dos professores de educação infantil sobre violência familiar contra criança ${ }^{1}$
}

\section{Training and knowledge of childhood education teachers on family violence against children}

\author{
Cléa Adas Saliba Garbin ${ }^{2}$ \\ Ana Paula Dossi de Guimarães e Queiroz ${ }^{3}$ \\ Adriana Alves Costa ${ }^{4}$ \\ Artênio José Isper Garbin ${ }^{5}$
}

\begin{abstract}
RESUMO
A violência contra crianças é apontada como uma das principais causas de morbi-mortalidade na infância e deve ser identificada por todos os profissionais que lidam com esse público, inclusive os professores. Objetivou-se avaliar o preparo dos professores de educação infantil, no que se refere à percepção e notificação dos casos de violência contra criança. Foram visitadas todas as instituições de ensino infantil de Araçatuba-SP, e os profissionais que consentiram ( $\mathrm{n}=236)$, os quais responderam a um questionário sobre $\mathrm{o}$ tema. Os dados foram analisados quanti-qualitativamente. $91,1 \%$ se consideram responsáveis pela notificação e $86,9 \%$ se dizem capazes de identificar agressões. $80,9 \%$ declararam ter recebido informações a respeito da violência contra criança, entretanto, $67,7 \%$ sentem-se inseguros quanto à identificação dos casos. Conclui-se que, mesmo possuindo formação para proceder ante
\end{abstract}

1 Pesquisa financiada pela Fundação de Amparo à Pesquisa do Estado de São Paulo - FAPESP - São Paulo, Brasil - (Iniciação Científica), processo número 08/51052-2

2 Professora Adjunta de Odontologia Legal e Bioética da Faculdade de Odontologia de Araçatuba (FOA) - Universidade Estadual Paulista (UNESP) - São Paulo, Brasil -E-mail: cgarbin@foa.unesp.br.

3 Professora Assistente Doutora de Odontologia Preventiva e Social - Faculdade de Odontologia de Araçatuba (FOA) - Universidade Estadual Paulista (UNESP) - São Paulo, Brasil - E-mail: anadossi@foa.unesp.br.

4 Aluna de graduação em Odontologia - Faculdade de Odontologia de Araçatuba (FOA) Universidade Estadual Paulista (UNESP), São Paulo, Brasil.

5 Professor Adjunto de Orientação Profissional da Faculdade de Odontologia de Araçatuba (FOA) - Universidade Estadual Paulista (UNESP), São Paulo, Brasil. 
a violência, a maioria dos pesquisados ainda não se sente preparada, o que pode gerar negligência.

Palavras-chave: violência doméstica; infância; educação infantil; formação de professores.

\begin{abstract}
Violence against children is pointed like one of the main causes of morbidity and mortality in childhood and should be identified by all professionals who deal with this public, including teachers. The aim was to evaluate the preparation of infantile education teachers, concerning the perception and notification of cases of violence against children. All the child educational institutions in Araçatuba-City, SP, Brazil were visited. The professionals who consented $(n=236)$, answered a questionnaire about that theme. The data was analyzed on the quantitative and qualitative form. $91.1 \%$ of professionals considered themselves responsible for notification and $86.9 \%$ feel themselves able to identify attacks. $80.9 \%$ had received information about violence against children; however, $67.7 \%$ feel insecure about the identification of cases. It was concluded that the most of professionals still don't feel themselves prepared to face violence, even having an early training and this can generate negligence.

Keywords: domestic violence; childhood; Childhood education; teacher training.
\end{abstract}

\title{
Introdução
}

A violência intrafamiliar tem vitimado alguns grupos mais vulneráveis como as crianças, os idosos e as mulheres (DOSSI et al., 2008, p. 1939). A criança maltratada é aquela vítima de violência física, crueldade mental, abuso sexual e negligência, com consequências graves para seu desenvolvimento físico e psicológico.

A agressão de uma criança em sua própria casa, local onde supostamente estaria protegida da violência, cria uma situação de profundo desamparo para a vítima. A obrigação de conviver com seu agressor e enfrentar o pacto do silêncio que costuma envolver as pessoas mais próximas nesse tipo de situação, são fatores que podem gerar efeitos catastróficos na formação da personalidade desses sujeitos que ainda não chegaram à fase adulta (FUNDAÇÃO ABRINQ, 2004, p.5). 
Trata-se de um problema cujas consequências são devastadoras, resultando em mortes precoces e traumas permanentes. Segundo dados da Organização Mundial de Saúde (OMS), em 2002, 53 mil crianças foram assassinadas no mundo inteiro. Além disso, no mesmo ano, cerca de 150 milhões de meninas e 73 milhões de meninos foram forçados a manter relações sexuais ou submetidos a outras formas de violência sexual envolvendo contatos físicos. Esses são dados alarmantes que deveriam preocupar o mundo todo a respeito do problema, todavia a sociedade aceita o fenômeno com complacência (MOURA, 2006, p.13).

As iniciativas de cooperação entre setores tão diversos como os da saúde, educação, serviços sociais, a justiça e a política são indispensáveis para resolver o problema da violência (KRUG et al., 2003, p.18). A criação de políticas para enfrentar esse problema no âmbito familiar tem sido uma preocupação do Estado brasileiro. Nesse sentido, pode-se destacar a criação de legislação específica, a exemplo, o Estatuto da Criança e do Adolescente, que trata dos direitos infantis (BRASIL, 1990). No entanto, mesmo com normas para reduzir essas ocorrências, o Brasil apresenta ainda altos índices de violência infantil, o que deixa clara a importância da mobilização dos vários setores da sociedade.

Entende-se que esse é um problema a ser tratado por todos os profissionais que lidam com essas crianças, inclusive os professores. Cada profissional, em sua respectiva área de atuação, tem por obrigação estar atento à ocorrência de possíveis casos de maus-tratos e violência sexual entre as crianças com quem convive, assim como médicos, psicólogos, fonoaudiólogos, dentistas e professores de educação infantil que, diariamente, relacionam-se com crianças (BRINO; WILLLIAMS, 2003, p.2; CARVALHO; TORREÃO, 1999, p.309; MORAES et al., 2002, p. 341; MOUDEN; BROSS, 1995, p.1174; NOGUCHI, et al., 2004, p. 965).

A violência diagnosticada e denunciada inicialmente pode salvar a vida e o futuro de muitas crianças que sofrem deste mal. A escola mostra-se em situação ideal para deteç̧ão e intervenção dos casos de abuso (BRINO; WILLIAMS, 2003, p. 2). A ênfase é dada aos professores de educação infantil, pois esses têm um contato direto e diário com essas crianças e podem auxiliar na prevenção das consequências da violência, justificando a realização deste estudo que buscou avaliar junto aos professores de educação infantil de um município do estado de São Paulo a formação, o conhecimento e a percepção deles sobre a violência intrafamiliar contra a criança. 


\section{$O$ contexto da pesquisa}

Foram realizadas visitas a cada unidade escolar para a entrega de ofício aos diretores com a finalidade de explicitar os objetivos do estudo, bem como obter a anuência deles para sua concretização ${ }^{6}$. Nessa mesma oportunidade, solicitou-se aos responsáveis uma listagem com o número de professores pertencentes a cada instituição.

No total, foram visitadas 59 Escolas de educação infantil, sendo 33 municipais e 26 pertencentes à rede privada de ensino, em Araçatuba, interior do estado de São Paulo. Os professores, depois de esclarecidos, foram convidados a participar do estudo.

O instrumento utilizado consistiu em um questionário semi-estruturado, contendo perguntas abertas e fechadas relativas ao conhecimento dos sinais e sintomas da violência, à obtenção de informações a respeito do tema e à atitude dos profissionais ante os casos. $\mathrm{O}$ questionário foi elaborado especialmente para a pesquisa e testado previamente. Para tanto, foram convidados a participar cerca de 30 professores que realizaram curso superior (Projeto Pedagogia Cidadã), na Universidade Estadual Paulista - UNESP - Araçatuba-SP. Depois do teste, o instrumento passou pelas adequações pertinentes. $^{7}$

Os dados foram digitados em uma planilha eletrônica criada no programa Epi Info, versão 3.5.1 (DEAN et al., 1990). Para a análise estatística utilizou-se o programa Bio Estat, versão 5.0 (AYRES et al., 2007).

$\mathrm{Na}$ análise qualitativa das questões abertas foi empregada a técnica Análise de Conteúdo, descrita por Bardin (2004, p.43) como "um conjunto de técnicas de análise de comunicação visando obter indicadores, por procedimentos sistemáticos e objetivos de descrição do conteúdo das mensagens, que permitam a inferência de conhecimentos relativos ao discurso dos entrevistados." A partir daí realizou-se, mais especificamente, a análise temática que consiste em

6 A realização da pesquisa foi autorizada mediante consentimento dos responsáveis pelas Secretarias Municipal e Estadual de Educação, sendo fornecidos os dados referentes às escolas pertencentes à amostra.

7 Previamente, o projeto foi submetido à apreciação do Comitê de Ética em Pesquisa da Faculdade de Odontologia de Araçatuba - SP - FOA-UNESP, sendo aprovado sob o Processo n. 2007-01343. 
descobrir núcleos de sentido, cuja presença e freqüência de aparição podem significar alguma coisa para o objetivo analítico escolhido por meio da categorização das respostas e análise em profundidade dos conteúdos manifestos pelos atores sociais envolvidos (MINAYO, 2006, p. 316).

\section{Resultados}

Do total de 326 professores de educação infantil do município, 236 (72,4\%) participaram do estudo. É Importante destacar que o acesso às escolas particulares foi mais intrincado; sendo que, em três delas, não foi permitida sequer a distribuição do instrumento.

No que se refere aos participantes, 70,8\% lecionam em escola pública; $22,0 \%$ em escola privada; $4,7 \%$ em ambas e $2,5 \%$ não responderam à questão. Quanto à idade, $21,2 \%$ possuem entre 20 e 29 anos; $41,5 \%$ entre 30 e $39 ; 21,2 \%$ entre 40 e $49 ; 6,4 \%$ têm 50 anos ou mais e $9,7 \%$ omitiram esse item. No que se refere ao tempo de experiência profissional, 70,8\% atuam na área há mais de 5 anos, sendo que desses, $132(80 \%)$ o fazem há mais de 10 anos.

Quanto ao recebimento de informações sobre a violência familiar contra a criança, $80,9 \%$ dos professores afirmaram tê-las recebido e $19,1 \%$ negaram. As informações foram obtidas: na graduação e/ou magistério $(36,1 \%)$; durante a pós-graduação $(6,3 \%)$; tanto na graduação quanto na pós $(5,8 \%)$; em palestras e cursos extras $(43,5 \%)$; no trabalho $(7,8 \%)$ e $0,5 \%$ não respondeu. Foram apontados professores, conselheiros tutelares e policiais como os principais responsáveis pelas informações.

Dentre os profissionais pesquisados, $86,9 \%$ afirmaram conhecer os sinais de violência nas crianças, enquanto que $6,4 \%$ alegaram não ter preparo para isso; $6,7 \%$ não responderam.

Sobre a notificação dos casos, $91,1 \%$ sentem-se responsáveis por esse ato, $7,2 \%$ acreditam não ter qualquer obrigação e $1,6 \%$ não responderam à questão. Dentre os que se sentem responsáveis, $31,5 \%$ consideram essa obrigação como algo inerente à profissão de educador; $19,1 \%$ acreditam ser um dever de todo cidadão o combate à violência; $19,1 \%$ por apresentar compaixão devido ao convívio com as crianças (Tabela 1). 
TABELA 1. - DISTRIBUIÇÃO NÚMERICA E PERCENTUAL DAS CATEGORIAS, SEGUNDO OS MOTIVOS QUE LEVAM OS PROFESSORES A SENTIR-SE RESPONSÁVEIS PELA NOTIFICAÇÃO DA VIOLÊNCIA CONTRA A CRIANÇA. ARAÇATUBA-SP, 2008.

\begin{tabular}{l|c|c}
\hline \multicolumn{1}{c|}{ Categoria } & n & \% \\
\hline $\begin{array}{l}\text { Obrigação inerente à profissão } \\
\text { "Faz parte da minha função como educadora" }\end{array}$ & 68 & 31,5 \\
\hline $\begin{array}{l}\text { Combate à violência } \\
\text { "Devemos combater este tipo de violência, denunciando" }\end{array}$ & 41 & 19,1 \\
\hline $\begin{array}{l}\text { Convivência com a criança } \\
\text { "Porque estou diariamente com ela" }\end{array}$ & 41 & 19,1 \\
\hline $\begin{array}{l}\text { Dever legal } \\
\text { "Porque é um dever que consta no Estatuto da criança e adolescente" }\end{array}$ & 23 & 10,7 \\
\hline $\begin{array}{l}\text { Não conivência } \\
\text { "Porque se eu não comunicar estarei sendo tão culpada, quanto } \\
\text { quem violentou" }\end{array}$ & 21 & 9,8 \\
\hline Não justificaram & 21 & 9,8 \\
\hline Total & $\mathbf{2 1 5}$ & $\mathbf{1 0 0}$ \\
\hline
\end{tabular}

Foi verificada associação significativa $(\mathrm{p}=0,0364)$ quando cruzados os dados relativos à obtenção de informações e ao sentimento de responsabilidade. Aplicou-se o teste exato de Fisher, no nível de significância de 5\%.

Quando questionados se se sentem preparados para identificar casos envolvendo crianças violentadas, $27,6 \%$ afirmaram que sim, 4,2\% disseram não, e $67,7 \%$ somente algumas vezes. A respeito dos motivos que fazem com que os profissionais se sintam inseguros ante a identificação da violência, foram distinguidas as seguintes categorias: a negativa da criança $(43,1 \%)$; a ausência de marcas físicas $(38,2 \%)$; a falta de conhecimento sobre o assunto $(10,0 \%)$, conforme descrito na tabela 2. 
TABELA 2 - DISTRIBUIÇÃO PERCENTUAL E ABSOLUTA DAS CATEGORIAS, SEGUNDO OS MOTIVOS QUE DIFICULTAMA IDENTIFICAÇÃO DA VIOLÊNCIA CONTRAA CRIANÇA. ARAÇATUBA-SP, 2008.

\begin{tabular}{l|c|c}
\hline \multicolumn{1}{c|}{ Categorias } & n & $\%$ \\
\hline $\begin{array}{l}\text { Quando a criança não demonstra } \\
\text { "Algumas vezes a criança, por medo, esconde bem” }\end{array}$ & 69 & 43,1 \\
\hline $\begin{array}{l}\text { Quando a agressão não deixa marcas físicas } \\
\text { "Porque nem toda agressão deixa marca visível” }\end{array}$ & 61 & 38,2 \\
\hline $\begin{array}{l}\text { Falta de conhecimento sobre o assunto } \\
\text { "Não tive nenhuma formação nesse assunto" }\end{array}$ & 16 & 10,0 \\
\hline $\begin{array}{l}\text { Quando os responsáveis negam } \\
\text { "Porque nem sempre os responsáveis pela criança confirmam } \\
\text { nossas suspeitas" }\end{array}$ & 5 & 3,1 \\
\hline Não responderam & 9 & 5,6 \\
\hline Total & $\mathbf{1 6 0}$ & $\mathbf{1 0 0}$ \\
\hline
\end{tabular}

\section{Discussão e conclusão}

As crianças e os adolescentes são as principais vítimas de todos os tipos de violência intrafamiliar (CAVALCANTI; MINAYO, 2004, p.484). A ideia de que o lar é o local de maior segurança e que confere proteção à criança, nem sempre é correta (RICAS et al., 2006, p.152).

Estudo recente realizado no município de Araçatuba evidenciou que as crianças (0-11 anos) e adolescentes (12-19 anos) representam grande parte das vítimas (34,3\% e 33,8\%, respectivamente) de agressões denunciadas entre pais/ responsáveis e seus filhos (DOSSI et al., 2008, p.1943). Dados mais abrangentes, representativos do estado de São Paulo, demonstram que a negligência e o abuso/violência sexual foram predominantes, sendo responsáveis por $34,0 \%$ e 33,6\% dos 776 casos de violência contra a criança e o adolescente notificados ao sistema de saúde, respectivamente (GAWRYSZEWSKI, et al., 2007, p.4).

Os dados descritos acima são provenientes de denúncias ou notificações. Entretanto, de acordo com a literatura, a maior parte dos casos de maus-tratos contra a criança ocorre no ambiente familiar, permanecendo, muitas vezes, silenciosos e inacessíveis. Essa relativa "invisibilidade" do problema ratifica a 
importância dos professores na identificação dessas situações, já que eles estão em contato com as crianças cotidianamente.

A violência quando identificada pelo sistema educacional traz importantes elementos para as autoridades competentes atuarem no combate ao problema. Entretanto, esse tema é pouco tratado nos currículos de cursos superiores (BRINO; WILLIAMS, 2003, p. 2).Tal fato pôde ser verificado neste estudo em que a maior parte dos pesquisados afirmou ter recebido informações sobre os sinais de violência em cursos extracurriculares. Essa constatação, aliada aos altos índices de violência contra crianças, enfatiza a necessidade de se abordar esse assunto de uma forma mais criteriosa ainda na graduação.

Além de uma adequada formação, a experiência profissional pode auxiliar na detecção dos casos. De maneira geral, os professores comprovaram a afirmação de que conhecem os sinais da violência infantil ao descreverem corretamente essas características, conhecimento que pode estar relacionado à grande experiência com a docência apresentada pela maior parte dos pesquisados.

Todavia, mais que o conhecimento, atitudes expectantes e uma capacidade acentuada de observação podem ser suficientes para diagnosticar sinais e sintomas de maus tratos. Deve-se suspeitar principalmente de lesões mal explicadas, que não condizem com as declarações dos familiares ou cuidadores.

O sentimento de responsabilidade quanto à notificação está, para a maior parte dos professores, relacionado ao dever profissional. Infelizmente, mesmo sendo a notificação reconhecida pela maioria como uma obrigação, ainda existe entre alguns a ideia de irresponsabilidade, o que demonstra, além do desconhecimento de suas atribuições, o descompromisso com a integridade e o bem-estar da criança. O sentimento de responsabilidade esteve significativamente associado ao recebimento de informações a respeito da violência, achado que reforça a ideia de que a inclusão desta temática na formação do educador é de fundamental importância para seu enfrentamento.

Verificou-se também certa insegurança dos professores quanto à identificação dos casos de violência o que, de certa forma, contrasta com a informação de que foram instruídos a respeito e sabem reconhecê-los. Isso pode estar associado à falta de clareza quanto aos conceitos e a uma ignorância quase completa da legislação sobre o assunto. Como resultado, existem profissionais totalmente despreparados para enfrentar os casos reais que se apresentam, temerosos de se posicionar diante destes e receosos de que o encaminhamento de uma suspeita resulte em um tipo de inconveniente legal para eles (LERNER, 2000, p. 30). É preciso conhecer os direitos da criança não somente para aumentar a percepção sobre o abuso, mas, principalmente, para que se tenha a atitude de denunciá-lo (BRINO; WILLIAMS, 2003, p. 2).

Dentre os motivos para tal insegurança, foram apontados principalmente: a negativa da criança quando questionada; a ausência de marcas físicas e a falta de conhecimento sobre esse tema. 
A agressão física é, sem dúvida, de mais fácil reconhecimento, todavia não é só essa forma de violência que pode desenvolver-se no interior das famílias. A violência psicológica tem-se mostrado muito frequente e exige atenção redobrada do profissional, já que sua manifestação, às vezes sutil, pode passar despercebida. Para tanto é necessário que além da atenção e da real disponibilidade para enfrentar a situação, os profissionais sejam capacitados de forma a identificá-la com segurança (SALIBA et al., 2007, p. 476).

Por meio da realização deste estudo pôde-se verificar que a maioria dos profissionais pesquisados recebeu informação a respeito da violência contra crianças e considera-se responsável pela sua notificação. Porém, grande parte ainda não se sente preparada para perceber esses casos, o que pode gerar negligência.

\section{REFERÊNCIAS}

AYRES, M. et al. BioEstat. Versão 5.0. Aplicações Estatísticas na área das ciências biomédicas. Sociedade Civil Mamirauá, MCT - CNPq, Belém, Pará, Brasil, 2007.

BARDIN, L. Análise de Conteúdo. 3. ed. Lisboa: Ed. 70, 2004.

BRASIL. Lei n. 8.069, de 13 de julho de 1990. Dispõe sobre o Estatuto da Criança e Adolescente e dá outras providências. Diário Oficial da República Federativa do Brasil, Brasília, DF, 16 jul. 1990. Seção I.

BRINO, R. F.; WILLIAMS, L. C. A. Capacitação de educadores acerca do abuso sexual infantil. Interação em Psicologia, Curitiba, v. 7, n. 2, p.1-10, 2003.

CARVALHO, P. R. A.; TORREÃO, L. A. Aspectos éticos e legais na emergência. Jornal de Pediatria, Rio de Janeiro, v.75, supl.2, p. 307-314, 1999.

CAVALCANTI, M. L. T.; MINAYO, M. C. S. Abordagem de violência intrafamiliar no Programa Médico de Família: dificuldades e potencialidades. In: BOSI, M. L. M.; MERCADO-MARTÍNEZ, F. J. (Orgs.). Pesquisa qualitativa de serviços de saúde. Petrópolis: Vozes, 2004. p.480-517.

DEAN, A. G.; DEAN, J. A.; BURTON, A. H.; DICKER, R. C. Epi Info, Version 6: a word processing, database and statistic program for epidemiology on microcomputers, Atlanta: Centers for Disease Control, 1990. 
DOSSI, A. P. et al. Perfil epidemiológico da violência física intrafamiliar: agressões denunciadas em um município do Estado de São Paulo, Brasil, entre 2001 e 2005. Cadernos de Saúde Pública, Rio de Janeiro, v.24, n.8, p.1939-1952, 2008.

FUNDAÇÃO ABRINQ. O fim da omissão: a implantação de pólos de prevenção à violência doméstica. São Paulo: Fundação Abrinq, 2004.

GAWRYSZEWSKI, V. P. et al. A violência contra crianças e adolescentes. Boletim Epidemiológico Paulista, v. 4, n. 37, jan. 2007. Disponível em: $<$ http:// www.cve.saude.sp.gov/agencia/bepa.htm>. Acesso em: 27/06/2009.

KRUG, E. G. et al. (Eds.). Informe mundial sobre la violencia y la salud. Washington: Organización Panamericana de la Salud, 2003.

LERNER, T. Tratamento em situações de abuso sexual de crianças e adolescentes. Jornal da Rede Saúde, São Paulo, n. 22, p. 29-32, 2000.

MINAYO, M. C. S. O desafio do conhecimento: pesquisa qualitativa em saúde. 3. ed. São Paulo: Hucitec, 2006.

MORAES CALDAS, I.; AFONSO, A.; MAGALHÃES, T. Os maus-tratos físicos em crianças e jovens: uma perspectiva médico dentária. Jornal Brasileiro de Odontologia e Clinica Integrada, Curitiba, v. 6, n. 34, p. 340-344, 2002.

MOUDEN, L. D.; BROSS, D. C. Legal issues affecting dentistry's role in preventing child abuse and neglect. Journal of the American Dental Association, Chicago, n. 8, v. 126, p.1173-1180, 1995.

MOURA, M. Violência sem limites. Pesquisa Fapesp, São Paulo, n.130, p.12-19, 2006.

NOGUCHI, M. S.; ASSIS, S. G.; SANTOS, N. C. Entre quatro paredes: atendimento fonoaudiólogo a crianças e adolescentes vítimas de violência. Ciência \& Saúde Coletiva, Rio de Janeiro, v. 9, n. 4, p. 963-973, 2004.

RICAS, J.; DONOSO, M. T. V.; GRESTA, M. L. M. A violência na infância como uma questão cultural. Texto \& Contexto. Enfermagem, Florianópolis, v. 15, n. 1, p. 151-154, 2006.

SALIBA, O. et al. Responsabilidade do profissional de saúde sobre a notificação de casos de violência doméstica. Revista de Saúde Pública, São Paulo,v. 41, n. 3, p. 472-477, 2007.

Texto recebido em 27 de abril de 2009.

Texto aprovado em 19 de julho de 2009. 